\title{
Analysis of the Ground Sinking around an Excavation Site using GPR Exploration
}

\author{
Yushik $\operatorname{Han}^{1}$ and Ki-Cheong Yoo ${ }^{2}$ \\ ${ }^{1,2}$ Geotechnical Engineering Research Institute of Korean Geotechnical Society, South Korea
}

\begin{abstract}
A sinkhole can be formed due to a number of causes. In particular, artificially induced sinkholes that are freq uently observed in Korea have been classified into different types. In this study, a sinkhole induced by groundwater level disturbance in an excavation site was analyzed, and the ground loosening region around the excavation site was also ana lyzed based on GPR(Ground Penetrating Radar) exploration. Due to groundwater discharge in the excavation site, groun $d$ loosening occurred in the surrounding ground area of the excavation site, and the ground loosening region was widely distributed over the surrounding ground with a groundwater level of more than $6.0 \mathrm{~m}$.
\end{abstract}

Keywords: Sinkhole, Ggroundwater level, Excavation site, GPR(Ground Penetrating Radar)

\section{Introduction}

With the development of cities, large-scale ground excavation works in urban area have rapidly increased, and accidents where the construction site or adjacent structure/facility have collapsed during excavation works have also frequently occurred. In Korea, there is currently no specific method for predicting/evaluating underground safety or evaluating the risk of ground sinking in relation to excavation work. Therefore, to promote systematic underground safety management and establish a relevant system to oversee such matters, the central government enacted the Special Act on Underground Safety Management in December 2015, and prepared to establish a professional institution for underground safety management (Han et al., 2016).

For ground excavation works in Korea, the major causes of collapse can be divided into 1. insufficient ground survey, 2. unstable temporary facility structure, 3. instability of the excavation floor surface due to boiling and heaving, 4 . instability due to inadequate groundwater treatment (e.g., water stoppage of blocking and drainage), 5. errors in the execution of works, 6. collapse due to excessive excavation, 7. collapse due to slope failure, and 8. collapse due to negligent management (KISTE, 2010). In the present study, for a case in which groundwater discharge induced ground settlement by changing the groundwater flow in the surrounding ground and by increasing the effective stress within the ground during the excavation work of a large-scale building, the ground loosening region was analyzed based on GPR exploration.

\section{Classification of Sinkholes}

A sinkhole refers to a phenomenon whereby the ground surface sinks to create a cylinder or funnel shape in the ground after the ground or underground cavity has collapsed. The cause of sinkholes due to the collapse of the ground or underground cavity can be categorized into two types: sinkholes brought about by natural causes and those brought about by artificial causes.

The occurrence of sinkholes by natural causes is as follows: acidification of surface water occurs when surface water absorbs carbon dioxide or participates in the metabolic activities of plants and such acidified surface water flows through bed rocks and weakens the structural integrity of the rocks. In particular, when bed 
rocks are composed of soft minerals such as limestone or carbonate rock, weakening of the structural integrity becomes more severe. Some of the typical types of naturally-caused sinkholes are ground collapse, ground subsidence, and ground dissolution.

Artificially sinkholes are caused by cavity expansion due to loosening ground and collapse during the underground construction of structures such as tunnels, underground cavity expansion due to defective compaction of backfill materials during construction of structures, and erosion due to water leakage in urban water supply and drainage pipes followed by expansion of an underground cavity and underground water disturbance. The classification of sinkholes according to this causal concept is shown in Fig. 1.

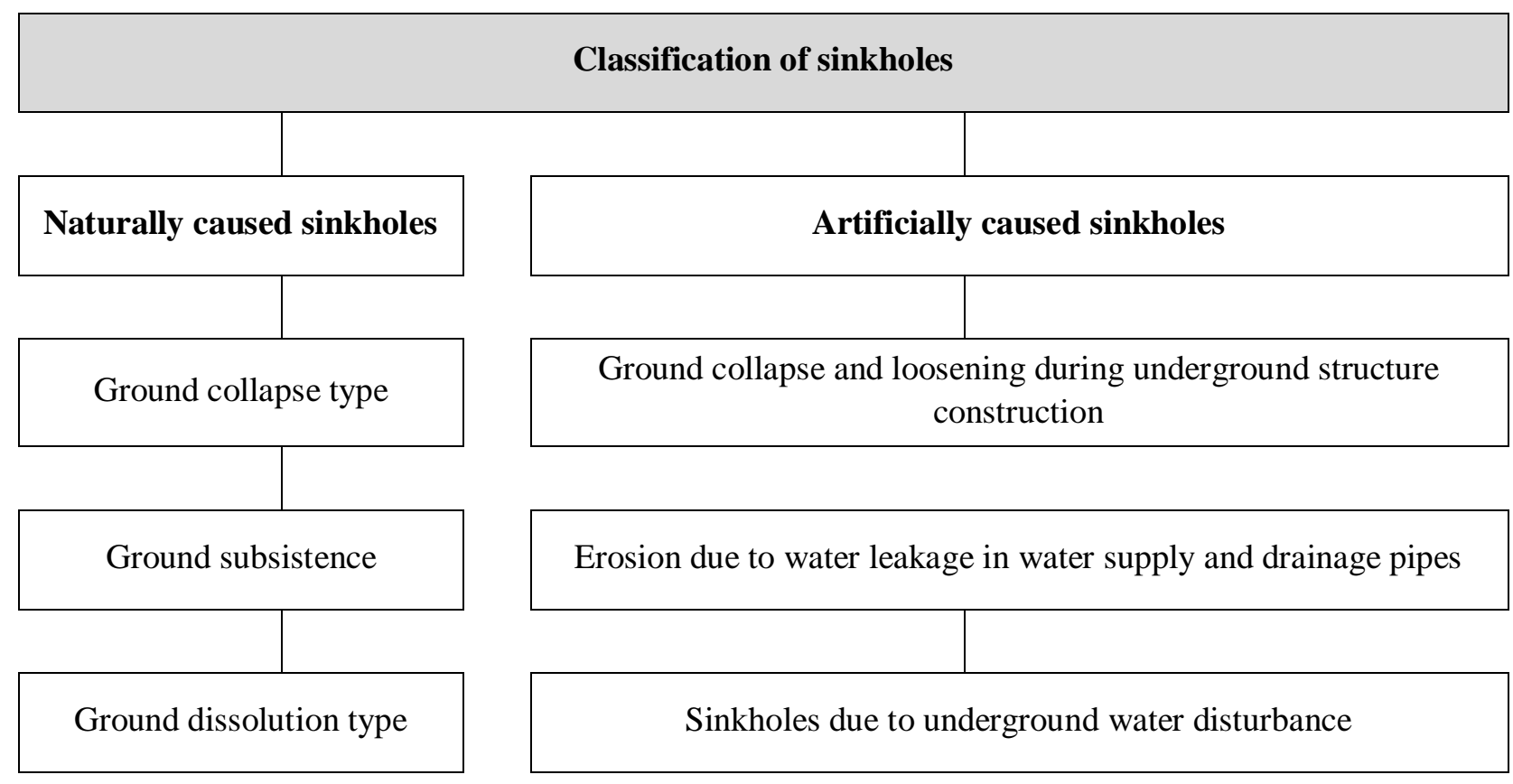

Fig. 1: Classification of sinkholes according to causal factors

\section{Analysis of the Cause of the Ground Sinking in the OO Area of Korea}

During the ground excavation work in the $\mathrm{OO}$ area, ground sinking and settlement occurred in the surrounding region.

As for the ground condition of the excavation site in the $\mathrm{OO}$ area (Fig. 2), the buried layer located between the ground surface and a depth of $7.5 \mathrm{~m}$ consists of loose sand and gravel mixed with silt, and it has an average $\mathrm{N}$ value of about 6 . Beneath the aforementioned layer, silty sand (SM) is distributed down to $22.5 \mathrm{~m}$. It is a very solid layer with an average $\mathrm{N}$ value of about 15 . Then, very dense gravelly sand with an average $\mathrm{N}$ value of more than 30 is distributed down to $25.0 \mathrm{~m}$, and soft rock is distributed beneath the gravelly sand. In addition, the groundwater level is located $10.0 \mathrm{~m}$ below the ground surface.

For the construction method of the excavation site, a diaphragm wall was used. A diaphragm wall is an earth retaining wall that is constructed by performing excavation in a wall shape using stabilizer liquid, followed by the insertion of mesh reinforcement and the placing of concrete. This method has outstanding water blocking property and high rigidity. Thus, it is appropriate for cases in which a large rear-side load is applied or ground deformation is problematic. However, in the case of soft ground, the excavation wall could easily collapse, and there are many difficulties in construction/management. 


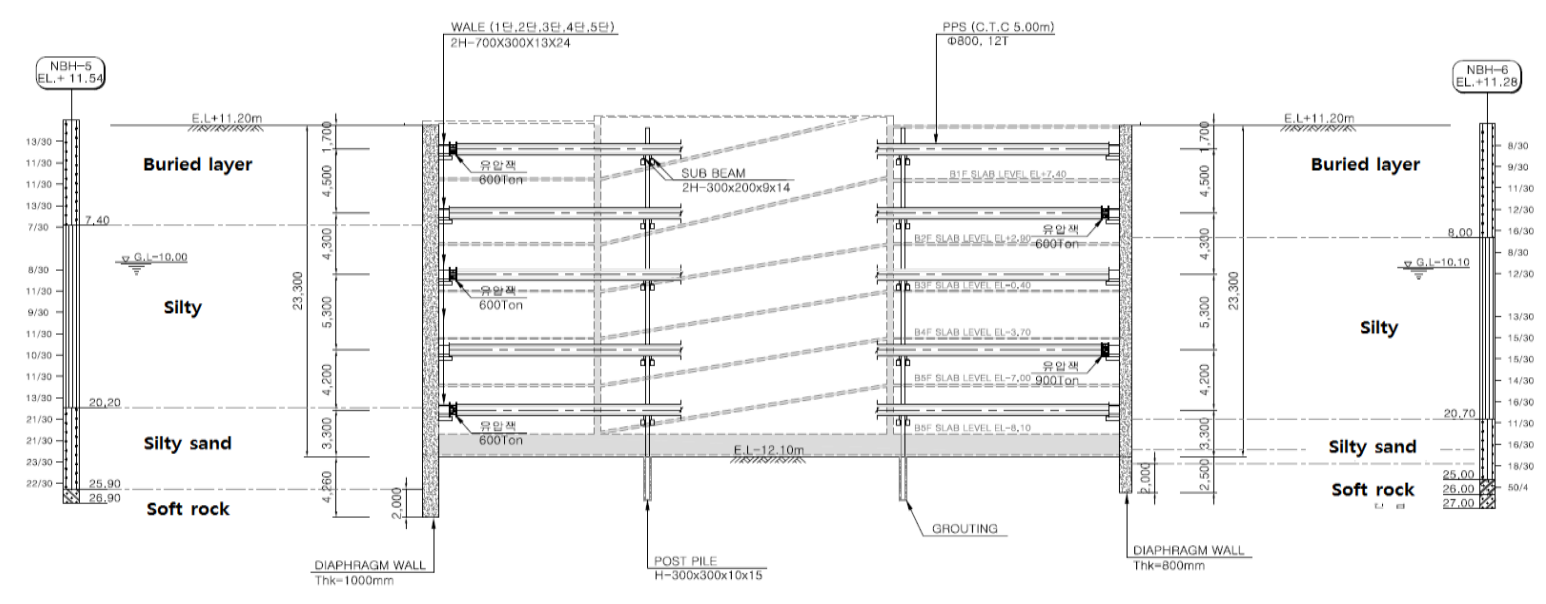

Fig. 2: Sectional view of the excavation plan

In the case of the initial ground sinking and road crack, groundwater was discharged from the first water leak joint position of the diaphragm wall that is $20 \mathrm{~m}$ below the ground surface (Fig. 3) at around 2:40 p.m., February 6, 2017, and the groundwater level decreased by $1.0 \mathrm{~m}$. In the first ground sinking occurrence region (Fig. 3), ground sinking $3 \mathrm{~m}$ in length and $30 \mathrm{~cm}$ in depth took place and a crack $30 \mathrm{~m}$ in length and $0.05 \sim 0.1 \mathrm{~m}$ wide was formed (Fig. 4(a)).

In the case of the second road crack and settlement event, groundwater was discharged from the second water leak joint position of the diaphragm wall that is about $20 \mathrm{~m}$ below the ground surface (Fig. 3) at around 6:30 p.m., February 14, 2017 during the reinforcement work in relation to the first accident, and the groundwater level decreased by about $6.0 \mathrm{~m}$. In the second ground settlement occurrence region (Fig. 3), a road crack and settlement that was $100 \mathrm{~m}$ in length were formed (Fig. 4(b)).

In the case of the third road crack event, a crack that was $20 \mathrm{~m}$ in length and $0.03 \sim 0.05 \mathrm{~m}$ wide was formed in the same region where the initial ground sinking event occurred, at around 3:20 p.m., February 22, 2017 (Fig. $4(c))$.

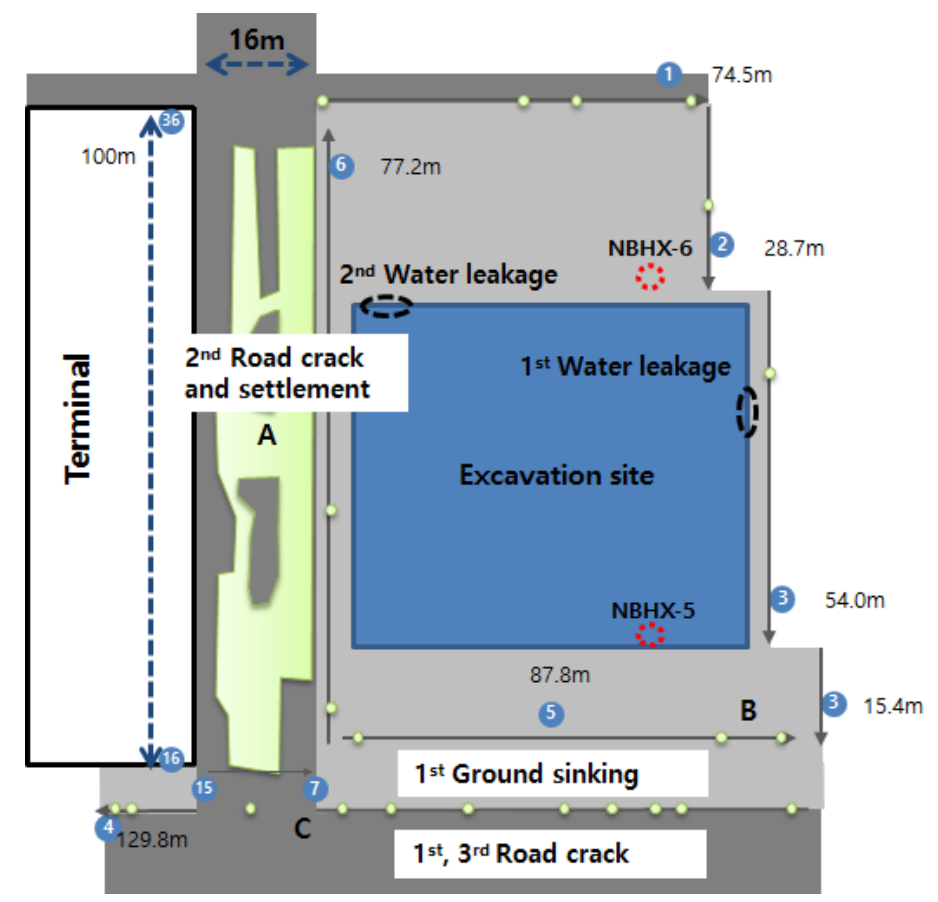

Fig. 3: Outline of the ground sinking in the $\mathrm{OO}$ area of Korea 


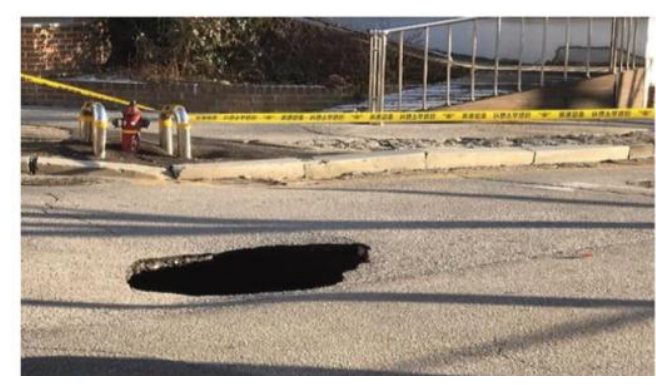

(a) First ground sinking

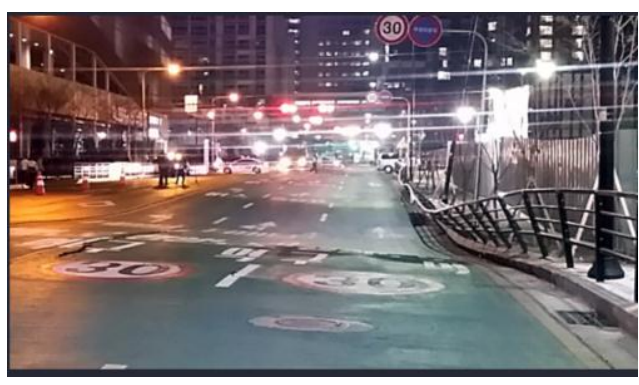

(c) Second road crack and settlement

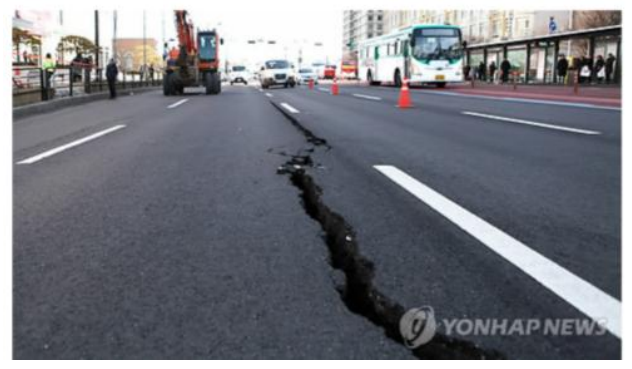

(b) First road crack

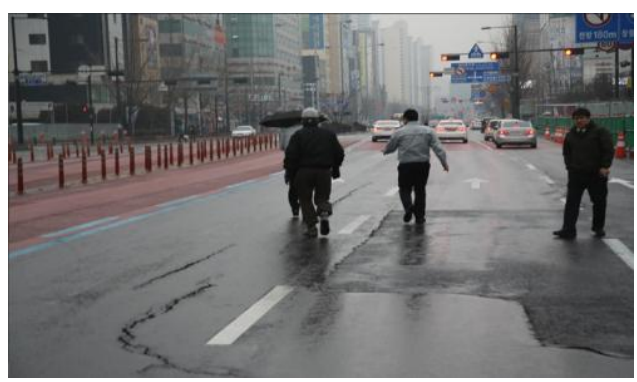

(d) Third road crack

Fig. 4: Ground sinking occurrence site

The surrounding region of the excavation site in Fig. 3 was examined using GPR exploration equipment (Mala 450MHz) on February 21, 2017, and the result showed that the surrounding ground of the excavation site was loosened. In particular, the ground loosening region was widely distributed underneath the road of the second ground settlement occurrence region (Fig. 5).

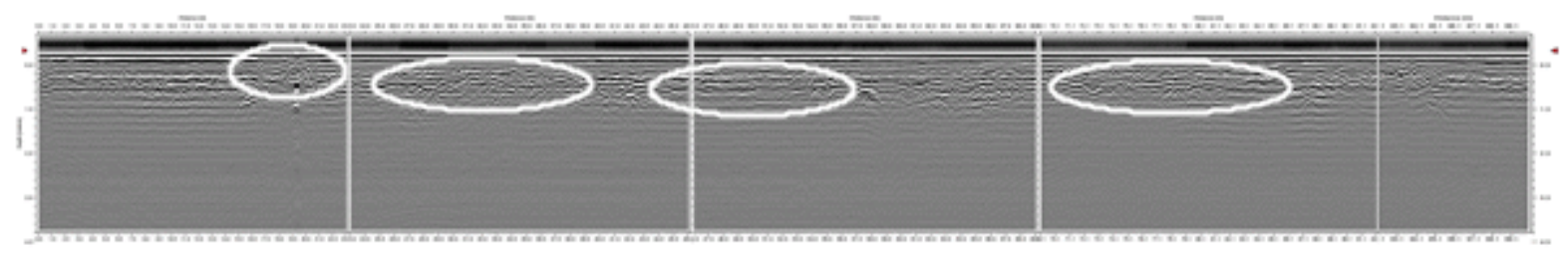

A

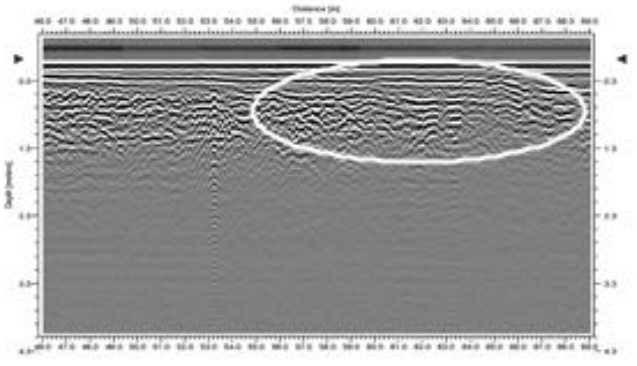

B

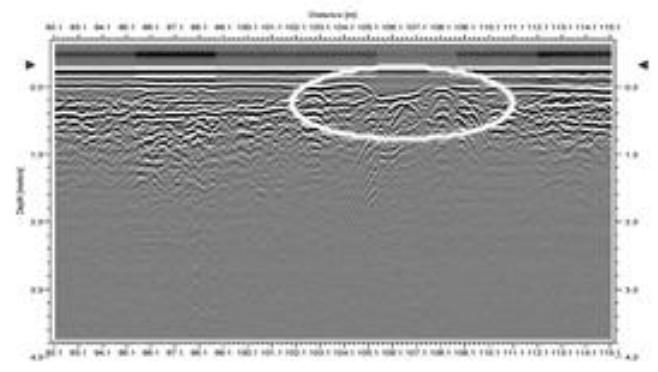

$\mathrm{C}$

Fig. 5: GPR Exploration Result 


\section{Conclusion}

The sinkhole that had occurred in the OO area in Korea was induced by an artificial factor, that is, it was due to groundwater level disturbance. The following conclusions can be drawn in relation to the cause of the accident.

1. In the $\mathrm{OO}$ area where the accident occurred, a water vein is located at a depth of $10 \sim 20 \mathrm{~m}$. It is thought that the sinking and settlement occurred in the surrounding ground because soil particles were discharged due to groundwater discharge induced by inappropriate installation of a cut-off wall during the excavation work.

2. Ground loosening occurred in the surrounding ground of the excavation site due to the groundwater discharge at the excavation site, and the ground loosening region was widely distributed over the surrounding ground with a groundwater level of more than $6.0 \mathrm{~m}$.

3. In addition, there is concern about long-term damage because the ground loosening region is evenly distributed around the ground excavation site.

\section{Acknowledgements}

This research was supported by the Korea Agency for Infrastructure Technology Advancement under the Ministry of Land, Infrastructure and Transport of the Korean government. (Project Number: 16SCIP-B10815302)

\section{References}

[1] Han, Y. S., Sohn, H. J., and Yoo, K. C, "Relationship Analysis of Volumetric Water Content According to the Dielectric Constant for Stability Analysis of Ground Excavation", Geophysics and Geophysical Exploration, Vol. 19, No. 3, p. 153 163, August, 2016.

[2] KISTEC, "A research for establishing safety management standards on neighboring facilities in accordance with ground excavation”, Korea Infrastructure Safety \& Technology Corporation, 2010, p. 77-214. 